\title{
Higher frequency of hamstring injuries in elite track and field athletes who had a previous injury to the ankle - a 17 years observational cohort study
}

Nikolaos Malliaropoulos ${ }^{1,2,3,4}$, Georgios Bikos ${ }^{2,6}$, Maria Meke ${ }^{1}$, Korakakis Vasileios ${ }^{7,8}$, Xavier Valle 9,10,11,12, Heinz Lohrer ${ }^{13,14}$, Nicola Maffulli ${ }^{5,15}$ and Nat Padhiar ${ }^{3,45^{*}}$ (1D

\begin{abstract}
Background: Inversion injury to the ankle and hamstring injuries are common problems in most sports. It is not known whether these injuries constitute a predisposing factor or a precursor of injury or re-injury of these anatomical locations. Therefore, we wished to test the hypothesis that a previous inversion ankle injury exerted a significant effect on the chance of an athlete suffering from a subsequent ipsilateral hamstring injury and vice versa.

Methods: In an observational cohort study over 17 years (1998-2015), 367 elite track and field athletes, were grouped according to their first traumatic isolated ankle or hamstring injury. Fifty athletes experienced both injuries. The MannWhitney $\mathrm{U}$ and Chi-square tests $(p<0.05)$ were performed to test possible associations of ankle and hamstring injury with age, gender, athletics discipline, grade, and type of antecedent injury.

Results: Athletes with a preceding ankle injury had a statistically significantly higher chance of experiencing a subsequent hamstring injury compared with athletes who had experienced a hamstring injury as their first traumatic event $\left(x^{2}=4.245\right.$, $p=0.039$ ). The proportion of both ankle and hamstring injury events was not statistically different between female (18\%) and male (11\%) athletes. Age and grade of injury did not influence the proportion of ankle and/or hamstring injury events.
\end{abstract}

Conclusion: There is a statistically significantly higher frequency of hamstring injuries in elite track and field athletes having experienced a previous ankle ligament injury.

Keywords: Ankle injuries, Hamstring injuries, Track and field athletes, Sports injuries

\section{What is known about the subject?}

To our knowledge, this is the first study that assessed the association between ankle and hamstring injuries and their predisposing role that each one of them has in a re-injury affecting the other location.

\section{What this study adds to existing knowledge}

The present study opens the way to investigate the relationship between injuries occurring in different parts of the musculoskeletal system but in the same limb.

\footnotetext{
* Correspondence: nat.padhiar@londonsportswise.co.uk

${ }^{3}$ European Sports Care, London, UK

${ }^{4}$ Sports Clinic, Rheumatology Department, Barts Health Trust, London, UK

Full list of author information is available at the end of the article
}

Athletes with a previous ankle injury face a higher risk of hamstring injury.

In clinical practice, there is a need for a holistic approach to musculoskeletal rehabilitation which should not be directed only to the region where a given injury occurred.

\section{Introduction}

Ankle sprains and hamstring muscle injuries are among the most common sport injuries, and are a major cause of time lost from sport participation [1-5].

The main mechanisms of hamstring injury is eccentric contraction at high velocity and slow stretching at outer range of motion [6]. A hamstring injury is a major risk 
factor for future hamstring injury [7-10]. Lateral ankle sprains are usually provoked by excessive foot inversion with the foot in plantar flexion [11]. Certain somatometric factors such as higher longitudinal foot arch, wider foot, cavovarus deformities of the foot may be associated with this injury [12]. Additionally, there is an association of the incidence of lateral ankle injuries with reduced cardiorespiratory endurance, decreased muscle strength and range of motion of ankle dosriflexors and decreased movement coordination [13].

There are several extrinsic risk factors for lower limb injuries such as level of competition, skill level, shoe type, ankle bracing and playing surface [14]. Intrinsic risk factors include age, gender, limb dominance, limb flexibility, body size, foot morphology, anatomical alignment of the lower limb, muscle tightness, joint laxity, aerobic fitness, postural stability and inadequate rehabilitation after previous musculoskeletal injury [14].

In addition, a recent systematic review concluded that a single ankle sprain is the most common injury resulting in a secondary sprain of the ipsi- or contralateral ankle [15].

Furthermore, a growing body of evidence links proximal and distal contributors/risk factors to lower extremity injury [16]. A pathomechanical model has been proposed, linking the biomechanics of the ankle joint with development of patellofemoral pain syndrome [17, 18], altered position and function of the hip and pelvis $[19,20]$ and the development of low back pain [21]. According to this model, excessive foot pronation delays external rotation of the tibia and disrupts timing between knee extension and rearfoot supination [18, 22, 23].

A link has also been suggested in terms of the role of proximal structures in biomechanical function of the lower limb and the development of lower extremity injury [24-26].

The core muscles (lumbar-pelvic hip complex) are essential in controlling hip abduction, subsequent femoral internal rotation, and potentially more distal movement [17, 27, 28].

There is nevertheless a gap in the literature evaluating whether a prior injury in the lower limb could be a predisposing factor for an injury occurring in a different location in the same lower limb.

This study compared and evaluated the events of first time unilateral hamstring and ankle injuries in elite track \& field athletes over a period of 17 years, and focused concurrently on both these injuries and their possible pathophysiological interdependence, while the majority of the studies reports on each of these injuries in isolation.

\section{Methods}

\section{Study design}

First-time traumatic ankle ligament injuries and hamstring muscle injuries in elite track \& field athletes were assessed through medical records at the Sports Medicine Clinic of National Team Elite Track \& Field Centre of Northern Greece in Thessaloniki. All injuries were recorded for a study period of 17 years (1998 to 2015) via a non-probability purposive sampling method. The Elite Track \& Field Centre and Sports Medicine Clinic, where data were collected, was the only centre that National Team elite track and field athletes were attending in the case of an injury. Weekly meetings with the national team coaches allowed the identification and follow up of each injured athlete and therefore, it was very unlikely for the sports medicine team not to be informed of any injury. The study was approved by the National Track \& Field Federation.

Finally, a total of 367 elite track \& field athletes aged 16 to 30 years, having visited the Sports Medicine Clinic of the National Team Elite Track \& Field Centre, were included. Relatively injured athletes were excluded if the injury was not related to ankle ligament or hamstrings, and if they participated in sports other than track and field (Fig. 1).

The athletes were grouped into four categories related to sport disciplines: sprinters $(100 \mathrm{~m}, 200 \mathrm{~m}, 400 \mathrm{~m}$, $110 \mathrm{~m}$ ), throwers (hammer, javelin, discus, shotput), jumpers (pole vault, long, triple and high jumps) and combined events athletes (decathlon, heptathlon).

Ankle injuries were classified in four grades according to Malliaropoulos et al. [29, 30] (Table 1).The measurement of oedema was performed using a measuring tape so that the following landmarks were crossed in a figure-of-eight fashion (Fig. 2): a) navicular tuberosity, b) the distal tip of the lateral malleolus, c) the distal tip of the medial malleolus and d) the base of the fifth metatarsal. The measurement was compared with the uninjured ankle, and it was expressed as oedema difference. Stress radiographs $[29,30]$ were performed in patients with a grade II and III injury with the knee positioned at 45 degrees of flexion and the foot in neutral to 5 degrees of plantar flexion. A $5 \mathrm{~kg}(\mathrm{Kg})$ weight was hanging from the lower third of the tibia [30].

In the hamstring injuries' group of athletes, the inclusion and exclusion criteria are described in Table 2 [31].

Hamstring injuries were classified in four grades according to Malliaropoulos et al. [32, 33] (Table 3).

Clinical assessment was conducted by a single certified fully trained Sport and Exercise physician, and included a detailed medical history (symptoms related to their sport, mechanism of the injury), a thorough clinical examination (including observation of stance and gait, 


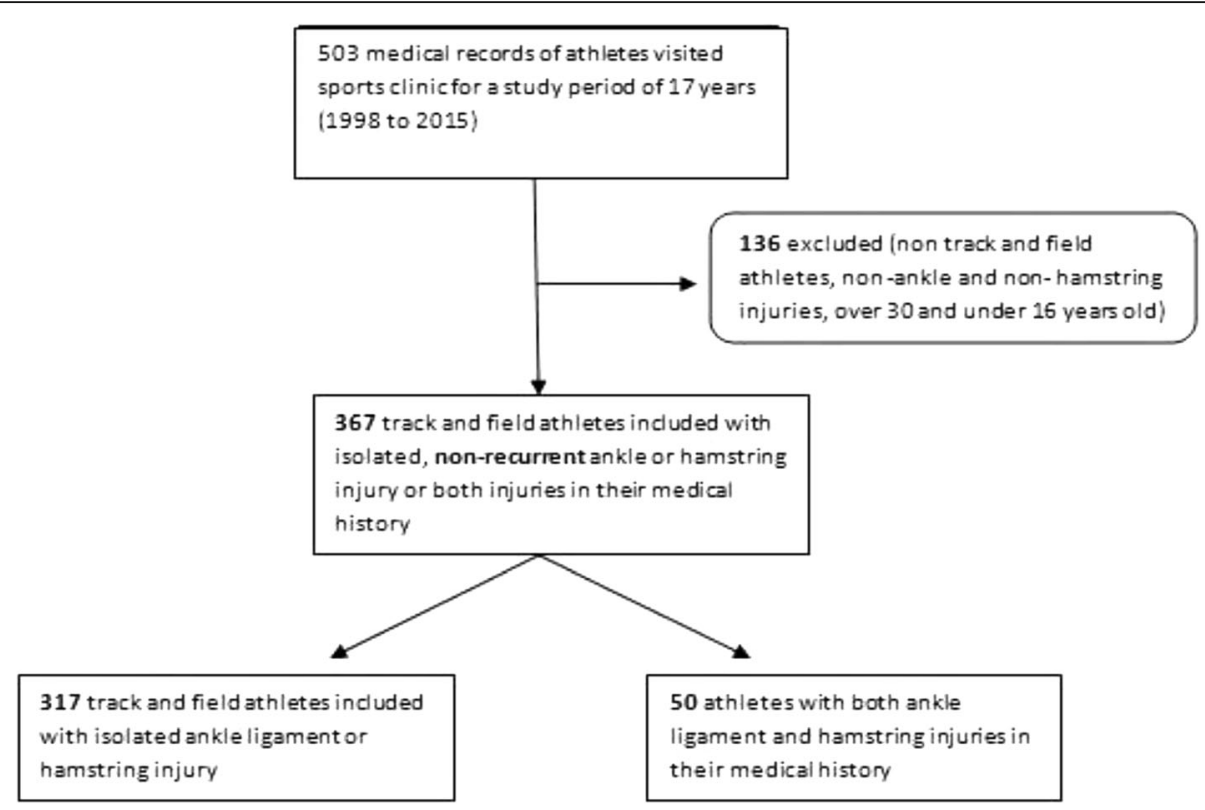

Fig. 1 Flowchart of the study population

palpation, range of motion, muscle strength testing and special diagnostic tests). Additionally, if required according to Ottawa ankle rules, athletes underwent diagnostic ultrasound and ankle radiographs [34].

\section{Study population}

During the data collection period, 367 elite track and field athletes, 225 (61.3\%) males and 142 (38.7\%) females, visited the Clinic reporting acute traumatic ankle and/or hamstring injuries. The athletes' mean age at their first visit was $20 \pm 3.2$ years (range 13 to 34 ).

Not reported athletic disciplines in elite track and field athletes' medical records were treated as elite track and field athletes' with missing discipline. A total of 144 runners, 99 jumpers, 19 throwers, 25 combined events athletes and 80 elite track and field athletes with missing information on their event discipline, were included in the study (Table 4).

\section{Statistical analysis}

Initially, all track and field athletes included were grouped in two categories according to the first traumatic event occurring in one of the two sites under study (ankle injury or hamstring injury). The athletes were then grouped in two categories indicating the occurrence of a traumatic event in both sites or in one of the sites over the time of the study. Frequencies and proportions were calculated and correlated with age, gender, athletic discipline and grade of injury, in both cases and based on the total of the 367 athletes having been injured either in one or in both sites under study.

The risk of the elite track and field athletes under study to experience either a hamstring or an ankle injury was calculated as an incidence proportion. Consequently, the numerator includes only new cases of hamstring or ankle injuries, whereas the denominator is the number of elite track and field athletes having been recorded and followed up during the observation period.

Therefore, the incidence proportion was estimated as follows: [35].

[(Number of events per type of injury) / (total of athletes during a specified period and registration terrain)*100].

The Mann-Whitney $U$ test was performed to assess possible associations between continuous and categorical

Table 1 Revised criteria for the classification of acute injury of the lateral ligament complex of the ankle compared to the uninjured side. Malliaropoulos et al. Foot Ankle Clinics 2006 Sep; 11(3):497-507

\begin{tabular}{llll}
\hline Grade & Decreased ROM & Edema difference & Stress radiographs \\
\hline I & Up to 5 degrees & Up to $0.5 \mathrm{~cm}$ & Normal \\
II & 5 to 10 degrees & $0.5 \mathrm{~cm}$ to $2 \mathrm{~cm}$ & Normal \\
IIIA (III) & More than 10 degrees & More than $2 \mathrm{~cm}$ & Normal \\
IIIB (IV) & More than 10 degrees & more than $2 \mathrm{~cm}$ & Laxity greater than $3 \mathrm{~mm}$ \\
\hline
\end{tabular}




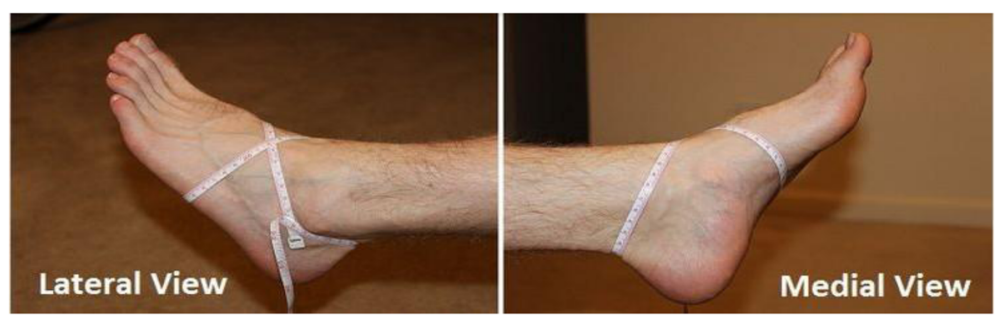

Fig. 2 Measurement of oedema in ankle injuries

data. The Chi-square test was performed to test possible associations between categorical variables. The Monte Carlo method was used in both cases to estimate the significance level. If there was a $2 \times 2$ table, exact results were provided instead of Monte Carlo. The basic assumption that 0 cells $(0.0 \%)$ should have expected a count less than 5 was accepted. Statistical analysis was conducted with Stata 12.0 statistical software and confidence level was set at 0.05 .

\section{Results}

There was a higher incidence of hamstring injuries (16.3\%, 245 incidents) compared with ankle injuries (8.1\%,122 incidents). The proportion of athletes having experienced both injuries accounted for 3.3\% (50 incidents out of 1500 athletes) of the total number of athletes with any type of injury.

Hamstring injuries experienced as first event accounted for $66.8 \%$ (245 athletes) and ankle injuries accounted for $33.2 \%$ (122 athletes), considering that there was no antecedent injury in these two areas. Most ankle injuries were clinical grade II (48.2\%), followed by grade I (24\%), and grade III (17.6\%). Similarly, a grade II injury was recorded in $53.6 \%$ of the hamstring injuries, followed by grade I (28.3\%) and grade III (15.1\%) (Fig. 3).

Age was not statistically significantly different between ankle and hamstring injuries reported as first injury $(\mathrm{U}=7674, p=0.692)$. Additionally, gender was not statistically significantly associated with the type of first injury recorded $(\times 2=3.492, p=0.324)$.

The athletic discipline was statistically significantly associated with the type of first injury $(\times 2=14.325, p=0.002)$.
Hamstring injuries were significantly more frequent than ankle injuries, especially in runners, jumpers, and combined sports events: $73.6 \%$ of the runners, $54.5 \%$ of the jumpers, and $72 \%$ of the combined events athletes experienced a hamstring injury as first injury (Fig. 4).

From a total of 367 elite track and field athletes who had experienced a first injury of the hamstring or of the ankle, 13.6\% (50 athletes out of 367 athletes) experienced both injuries over the data collection period (Fig. 5). Athletes with a preceding ankle injury $(23 / 122=19 \%)$ had a higher chance of experiencing a subsequent hamstring injury compared with athletes who had experienced a hamstring injury as the first traumatic event $(27 / 245=11 \% ; \times 2=4.245, p=0.039)$.

Athletic discipline $(\times 2=3.025, p=0.388)$ and gender $(\times 2=3.120, p=0.77)$ did not significantly affect the number of athletes experiencing both ankle and hamstring injuries. The proportion of athletes experiencing both ankle and hamstring injury events was 18\% (25 of 142) in females and $11 \%$ (25 of 225) in male athletes. The clinical grade of ankle or hamstring injury did not influence the subsequent traumatic event to occur in the different area $(\times 2=7.633, p=0.54)$.

\section{Discussion}

To our knowledge, this is the first study that assessed the interdependence of acute traumatic ankle and hamstring injuries and their predisposing role in a re-injury affecting the other location. The most important finding of this study was the fact that athletes with a previous ankle injury had higher proportion of a subsequent first injury in the hamstrings compared with athletes with a

Table 2 Inclusion and exclusion criteria for the hamstring injury group (Malliaropoulos et al. Br J Sports Med 2014; 48:22 1607-1612)

\begin{tabular}{ll}
\hline Inclusion criteria & Exclusion criteria \\
\hline Acute injury & Uncertain clinical diagnosis \\
Local tenderness & Verified or previously suspected posterior thigh muscle injury \\
Pain with resisted knee flexion or resisted hip extension & Pain on palpation at the origin or insertion of the posterior thigh muscles
\end{tabular}

Pain with passive hip flexion with the knee extended

Provocation of pain on isometric contraction of posterior thigh muscles 
Table 3 Classification of posterior thigh muscle injury according to active range of motion deficit of knee extension. Malliaropoulos et al. Am J Sports Med. 2010 Sep; 38(9):1813-9

\begin{tabular}{ll}
\hline Clinical grade & Active ROM deficit \\
\hline II & Up to 9 degrees \\
III & 10 to 19 degrees \\
IV & 20 to 29 degrees \\
\hline
\end{tabular}

previous hamstring injury and a subsequent ankle injury $(p<0.05)$. Also, athletes who first suffered from an ankle injury were at greater risk of further ankle injuries. This study does not answer the question, why a hamstring injury following ankle injury is more common than an ankle injury following hamstring injury. This interesting finding has to be investigated in further prospective research.

Generally, injury rates increase with the number of preceding injuries [36]. Furthermore, psychosocial factors such as risk-taking behaviour, life event stress and trait anxiety may contribute to an increased risk of reinjury even in a different location $[37,38]$.

Lower extremity injuries are multifactorial [39], and depend on several intrinsic (athlete-related) and extrinsic (environmental) factors. In some instances, intrinsic factors have proven more predictive of muscle strain injury than extrinsic factors [40]. In the present study, the frequency of both ankle and hamstring injury events was greater in female $(18 \%)$ than in male $(11 \%)$ athletes, although the difference was not statistically significantly. Interestingly, age did not influence the proportion of ankle and/or hamstring injury events.

Up to now, the literature has not associated directly ankle and hamstring injury, even though there is evidence to suggest that previous calf muscle injury is independently predictive of hamstring muscle injury. After injury, changes may occur in the functional biomechanics of the lower limb, predisposing the athletes to injury in different muscle groups. Accordingly, altered lower limb biomechanics have been reported in gait, unilateral stance and functional testing after ankle sprain injuries compared with controls [40].

A significant increase in ankle joint inversion and a reduction in joint plantar flexion during gait have been found in patients following lateral ankle sprain [41]. Limited ankle dorsiflexion has also been proposed as a predictor for lateral ankle sprain [42]. Kinetic and kinematic alterations were observed, and were attributed to an increased reliance on more proximal structures (knee and hip) to absorb impact forces [41]. Patients with a 6 month history of first-time lateral ankle sprain displayed a greater hip-dominant coordination strategy for static unilateral stance [43] and greater hip extensor dominance during drop jumps [44]. The observed flexor movement produced during the initial phase of the drop jumps may have led to a force attenuation strategy following initial contact [44]. A plausible explanation could be given for the findings of the present study by the fact that $32-74 \%$ of individuals with a history of ankle sprain report residual and chronic symptoms and aberrancy of sensorimotor variables of neuromuscular control [45-47]. This situation alters lower limb biomechanics in the injured ankle and affects proximal muscle groups such as hamstrings [48]. Previous injury in the lower extremity, especially when followed by inadequate rehabilitation, is a risk factor for further injuries to the ankle, knee, and to the ipsilateral lower extremity in general [14].

Regarding athletes with a prior history of acute ankle injury, neurophysiological changes have been reported

Table 4 Population sport events and gender

\begin{tabular}{|c|c|c|c|c|c|c|c|c|}
\hline & & & \multicolumn{5}{|c|}{ Athletic discipline } & \multirow[t]{2}{*}{ Total } \\
\hline & & & Runners & Jumpers & Throwers & Combined & Elite Track \& Field athletes (missing discipline) & \\
\hline \multirow[t]{8}{*}{ Gender } & \multirow[t]{4}{*}{ Male } & Number & 81 & 67 & 12 & 14 & 51 & 225 \\
\hline & & $\%$ within Gender & $36.0 \%$ & $29.8 \%$ & $5.3 \%$ & $6.2 \%$ & $22.7 \%$ & $100.0 \%$ \\
\hline & & $\%$ within Athletic discipline & $56.2 \%$ & $67.7 \%$ & $63.2 \%$ & $56.0 \%$ & $63.8 \%$ & $61.3 \%$ \\
\hline & & $\%$ of Total & $22.1 \%$ & $18.3 \%$ & $3.3 \%$ & $3.8 \%$ & $13.9 \%$ & $61.3 \%$ \\
\hline & \multirow[t]{4}{*}{ Female } & Number & 63 & 32 & 7 & 11 & 29 & 142 \\
\hline & & $\%$ within Gender & $44.4 \%$ & $22.5 \%$ & $4.9 \%$ & $7.7 \%$ & $20.4 \%$ & $100.0 \%$ \\
\hline & & $\%$ within Athletic discipline & $43.8 \%$ & $32.3 \%$ & $36.8 \%$ & $44.0 \%$ & $36.2 \%$ & $38.7 \%$ \\
\hline & & $\%$ of Total & $17.2 \%$ & $8.7 \%$ & $1.9 \%$ & $3.0 \%$ & $7.9 \%$ & $38.7 \%$ \\
\hline \multirow[t]{4}{*}{ Total } & & Number & 144 & 99 & 19 & 25 & 80 & 367 \\
\hline & & $\%$ within Gender & $39.2 \%$ & $27.0 \%$ & $5.2 \%$ & $6.8 \%$ & $21.8 \%$ & $100.0 \%$ \\
\hline & & $\%$ within Athletic discipline & $100.0 \%$ & $100.0 \%$ & $100.0 \%$ & $100.0 \%$ & $100.0 \%$ & $100.0 \%$ \\
\hline & & $\%$ of Total & $39.2 \%$ & $27.0 \%$ & $5.2 \%$ & $6.8 \%$ & $21.8 \%$ & $100.0 \%$ \\
\hline
\end{tabular}




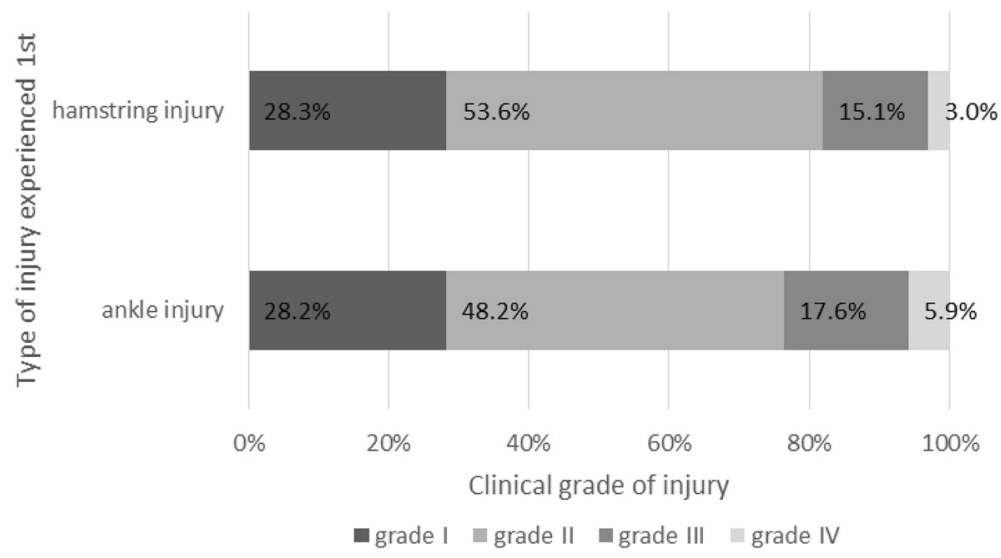

Fig. 3 Proportion according to grades of ankle and hamstring injury

in the ipsilateral posterior thigh muscles [49-51]. Additionally, mechanical instability of the ankle joint leads to an increased inversion, predisposing to further ankle sprain injury [52].

Evidence suggests at least an indirect biomechanical link between specific regions of the leg. Tight hamstring muscles have been associated with plantar fasciitis $[45,48,53]$. Increased hamstring tightness causes early contraction of the posterior leg muscles through the gait cycle, and decreases ankle dorsiflexion [54, 55] which in turn induces prolonged forefoot loading and the increased magnitude of tensile loading forces within the plantar fascia [45].

There is need for further studies on the interdependence of injuries in these specific anatomic sites. The outcome of the current study underlines the need for consequent rehabilitation of ankle and hamstring muscle injuries. Further research should address the interferences between hamstring and ankle injuries. In addition, it seems reasonable to elucidate, if the observed injury associations also occur in different sports (e.g. football). The question, if the demonstrated relations are also true for recreational athletes has also to be answered in future investigations. Probably, there is also an influence of a specific injury to induce a contralateral lesion.

\section{Conclusion}

The study population of elite track and field athletes showed a significantly higher frequency of hamstring injuries if an athlete had sustained a prior traumatic acute ankle injury compared with athletes who initially had posterior thigh muscle injury and secondarily suffered an ankle joint injury. Given the present findings, rehabilitation programmes should focus on improvement of proprioception and strength of the whole lower extremity after ankle injuries.

In addition, the association between injuries occurring in different parts of the musculoskeletal system needs to be investigated further.

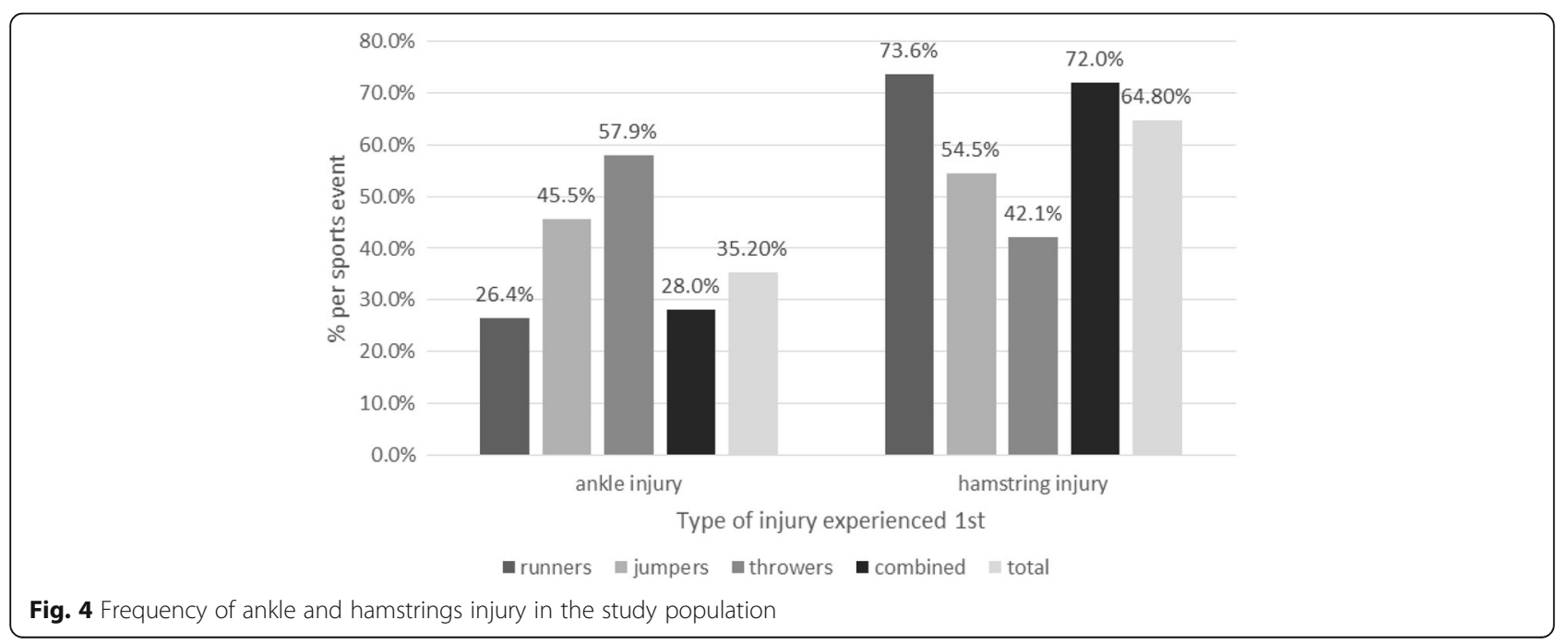




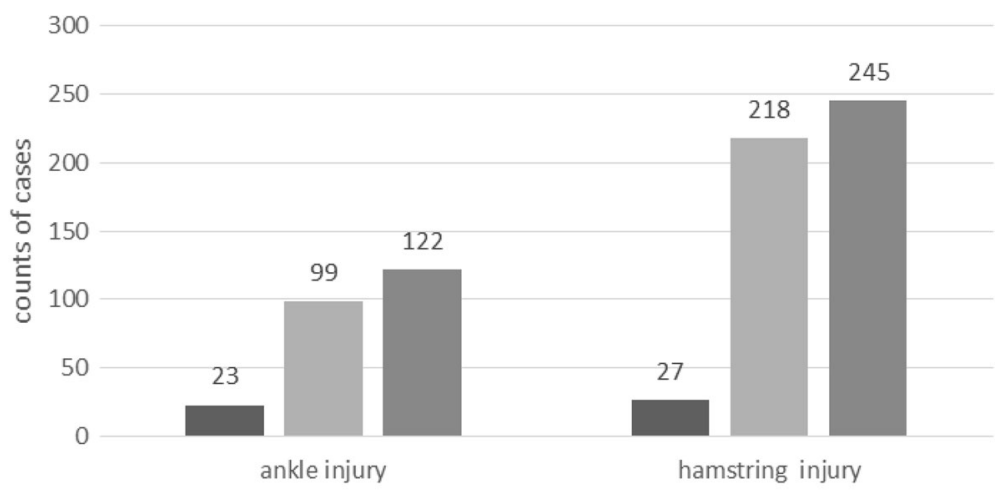

Type of injury experienced 1st

- both ankle and hamstring injury = single ankle or hamstring injury = total

Fig. 5 Frequency of single ankle or hamstring injury, and ankle and hamstring injury

\section{Limitations}

One limitation of the study was the fact that 80 athletes did not report their sport discipline. However, their injuries were recorded in detail, and therefore it does not bear any consequence on the main study question.

Recall bias regarding correct reporting of first injury was also likely to be present during the follow up period. Also, the grading of severity of the two injuries is not homogeneous, so, for example, a grade II ankle injury is not comparable, in terms of severity and recovery time, to a grade II hamstring injury. Another potential confounder was the heterogeneity of the study population. Although all included subjects were elite track and field athletes, they were divided in different sport disciplines with different load demands to the lower extremities.

\section{Abbreviations}

Kg: Kilogram; UK: United Kingdom

\section{Acknowledgments}

We thank the Greek Track and Field Federation for approving this study and we also thank all the subjects who gave their consent and understood the importance of this study.

\section{Funding}

There are no funding issues. This research received no specific grant from any funding agency in the public, commercial, or not-for-profit sectors. relevant, registered) have been explained. Consent was not obtained but the presented data are anonymised and risk of identification is low.

\section{Availability of data and materials}

There are no issues concerning this as strict confidentiality was observed and subjects were anonymised. The authors affirm that this manuscript is an honest, accurate, and transparent account of the study being reported; that no important aspects of the study have been omitted; and that any discrepancies from the study as planned (and, if relevant, registered) have been explained.

\section{Authors' contributions}

This was a collaborative study. All authors contributed to conception and design of the study, interpretation of the data, as well as drafting and writing the manuscript and final approval. NM planned the study, collect the data, contributed to manuscript writing, GB contributed to manuscript writing and statistical and Data analysis and MM performed the statistical analysis. VK contributed to manuscript writing and acquisition of the data, HL, XV and NP were involved in acquisition of the data. NM supervised the data collection, data analysis and manuscript writing. All authors agree to be accountable for all aspects of the work. All authors read and approved the final manuscript.

Ethics approval and consent to participate

Ethical approval for this retrospective uncontrolled study was granted and approved by the Greek Track and Field Federation Review Board. ART No. 1998-11. All athletes provided written informed consent prior to participating in the study.

\section{Consent for publication}

Participants and Greek Track and Field Federation were aware that findings will be disseminated at conferences and results will be published.

\section{Competing interests}

The authors declare that they have no competing interests.

\section{Publisher's Note}

Springer Nature remains neutral with regard to jurisdictional claims in published maps and institutional affiliations.

\section{Author details}

${ }^{1}$ Sports and Exercise Medicine Clinic, Thessaloniki, Greece. ${ }^{2}$ National Track \& Field Centre, Sports Medicine Clinic, Thessaloniki, Greece. ${ }^{3}$ European Sports Care, London, UK. ${ }^{4}$ Sports Clinic, Rheumatology Department, Barts Health Trust, London, UK. ${ }^{5}$ William Harvey Research Institute, Centre for Sports and Exercise, Barts and The London School of Medicine and Dentistry, Queen Mary, University of London, London, UK. ${ }^{6}$ Euromedica Arogi Rehabilitation Clinic, Thessaloniki, Greece. ${ }^{7}$ Aspetar, Orthopaedic and Sports Medicine Hospital, Doha, Qatar. ${ }^{8}$ Hellenic Orthopaedic Manipulative Therapy Diploma, Athens, Greece. ${ }^{9}$ Football Club Barcelona, Medical Department, Barcelona, Spain. ${ }^{10}$ Sports Medicine School (Universitat de Barcelona), Barcelona, Spain. ${ }^{11}$ Mapfre Centre for Tennis Medicine, Barcelona, Spain. ${ }^{12}$ Department de Cirurgia de la Facultat de Medicina at the Universitat Autònoma de Barcelona, Barcelona, Spain. ${ }^{13}$ European SportsCare Network, Frankfurt am Main, Germany. ${ }^{14}$ Department of Sport and Sport Science, University of Freiburg, Freiburg im Breisgau, Germany. ${ }^{15}$ Department of Musculoskeletal Disorders, Faculty of Medicine and Surgery, University of Salerno, Salerno, Italy.

Received: 6 July 2017 Accepted: 22 January 2018

Published online: 26 February 2018

\section{References}

1. Brooks JH, Fuller CW, Kemp SP, Reddin DB. Incidence, risk, and prevention of hamstring muscle injuries in professional rugby union. Am J Sports Med. 2006;34:1297-306 
2. Cloke DJ, Spencer S, Hodson A, Deehan D. The epidemiology of ankle injuries occurring in English football association academies. Br J Sports Med. 2009;43:1119-25

3. Ekstrand J, Hagglund M, Walden M. Epidemiology of muscle injuries in professional football (soccer). Am J Sports Med. 2011;39:1226-32.

4. Feddermann-Demont N, Junge A, Edouard P, Branco P, Alonso JM. Injuries in 13 international athletics championships between 2007-2012. Br J Sports Med. 2014;48:513-22.

5. Ferran NA, Maffulli N. Epidemiology of sprains of the lateral ankle ligament complex. Foot Ankle Clin. 2006;11:659-62.

6. Orchard J, Best TM, Verrall GM. Return to play following muscle strains. Clin J Sport Med. 2005;15:436-41.

7. Brockett $\mathrm{CL}$, Morgan $\mathrm{DL}$, Proske U. Predicting hamstring strain injury in elite athletes. Med Sci Sports Exerc. 2004;36:379-87.

8. Gabbe BJ, Bennell KL, Finch CF, Wajswelner H, Orchard JW. Predictors of hamstring injury at the elite level of Australian football. Scand J Med Sci Sports. 2006;16:7-13.

9. Opar DA, Williams MD, Shield AJ. Hamstring strain injuries: factors that lead to injury and re-injury. Sports Med. 2012;42:209-26.

10. Willson JD, Dougherty CP, Ireland ML, Davis IM. Core stability and its relationship to lower extremity function and injury. J Am Acad Orthop Surg. 2005;13:316-25.

11. Ivins D. Acute ankle sprain: an update. Am Fam Physician. 2006;74:1714-20.

12. Willems TM, Witvrouw E, Delbaere K, Mahieu N, De Bourdeaudhuij I, De Clercq D. Intrinsic risk factors for inversion ankle sprains in male subjects: a prospective study. Am J Sports Med. 2005;33:415-23.

13. Morrison KE, Kaminski TW. Foot characteristics in association with inversion ankle injury. J Athl Train. 2007;42:135-42.

14. Murphy DF, Connolly DA, Beynnon BD. Risk factors for lower extremity injury: a review of the literature. Br J Sports Med. 2003;37:13-29.

15. Fulton J, Wright K, Kelly M, Zebrosky B, Zanis M, Drvol C, Butler R. Injury risk is altered by previous injury: a systematic review of the literature and presentation of causative neuromuscular factors. Int J Sports Phys Ther. 2014:9:583-95.

16. Chuter $\mathrm{VH}$, Janse de Jonge XA. Proximal and distal contributions to lower extremity injury: a review of the literature. Gait Posture. 2012;36:7-15.

17. Levinger $P$, Gilleard W. Tibia and rearfoot motion and ground reaction forces in subjects with patellofemoral pain syndrome during walking. Gait Posture. 2007; 25:2-8

18. Tsaklis P, Malliaropoulos N, Mendiguchia J, Korakakis V, Tsapralis K, Pyne D, Malliaras P. Muscle and intensity based hamstring exercise classification in elite female track and field athletes: implications for exercise selection during rehabilitation. Open Access J Sports Med. 2015;6:209-17.

19. Cichanowski HR, Schmitt JS, Johnson RJ, Niemuth PE. Hip strength in collegiate female athletes with patellofemoral pain. Med Sci Sports Exerc. 2007;39:1227-32

20. Khamis S, Yizhar Z. Effect of feet hyperpronation on pelvic alignment in a standing position. Gait Posture. 2007;25:127-34.

21. Rothbart B, Hansen K, Liley P, Yerratt M. Resolving chronic low back pain. The foot connection. Am J Pain Manage. 1995;5:84-90.

22. Hamill J, Bates BT, Holt KG. Timing of lower extremity joint actions during treadmill running. Med Sci Sports Exerc. 1992;24:807-13.

23. Stergiou N, Bates BT, James SL. Asynchrony between subtalar and knee joint function during running. Med Sci Sports Exerc. 1999;31:1645-55.

24. Ireland ML, Willson JD, Ballantyne BT, Davis IM. Hip strength in females with and without patellofemoral pain. J Orthop Sports Phys Ther. 2003;33:671-6.

25. Willson JD, Ireland ML, Davis I. Core strength and lower extremity alignment during single leg squats. Med Sci Sports Exerc. 2006;38:945-52.

26. Zazulak BT, Hewett TE, Reeves NP, Goldberg B, Cholewicki J. Deficits in neuromuscular control of the trunk predict knee injury risk: a prospective biomechanical-epidemiologic study. Am J Sports Med. 2007;35:1123-30.

27. Fredericson $M$, Cookingham $C L$, Chaudhari AM, Dowdell BC, Oestreicher $N$, Sahrmann SA. Hip abductor weakness in distance runners with iliotibial band syndrome. Clin J Sport Med. 2000;10:169-75.

28. Nadler SF, Malanga GA, DePrince M, Stitik TP, Feinberg JH. The relationship between lower extremity injury, low back pain, and hip muscle strength in male and female collegiate athletes. Clin J Sport Med. 2000;10:89-97.

29. Malliaropoulos N, Ntessalen M, Papacostas E, Longo UG, Maffulli N. Reinjury after acute lateral ankle sprains in elite track and field athletes. Am J Sports Med. 2009;37:1755-61.

30. Malliaropoulos N, Papacostas E, Papalada A, Maffulli N. Acute lateral ankle sprains in track and field athletes: an expanded classification. Foot Ankle Clin. 2006;11:497-507.
31. Malliaropoulos N, Korakakis V, Christodoulou D, Padhiar N, Pyne D, Giakas G, Nauck T, Malliaras P, Lohrer H. Development and validation of a questionnaire (FASH-functional assessment scale for acute hamstring injuries): to measure the severity and impact of symptoms on function and sports ability in patients with acute hamstring injuries. Br J Sports Med. 2014;48:1607-12.

32. Malliaropoulos N, Isinkaye T, Tsitas K, Maffulli N. Reinjury after acute posterior thigh muscle injuries in elite track and field athletes. Am J Sports Med. 2011;39:304-10.

33. Malliaropoulos N, Papacostas E, Kiritsi O, Papalada A, Gougoulias N, Maffulli N. Posterior thigh muscle injuries in elite track and field athletes. Am J Sports Med. 2010;38:1813-9.

34. Papacostas E, Malliaropoulos N, Papadopoulos A, Liouliakis C. Validation of Ottawa ankle rules protocol in Greek athletes: study in the emergency departments of a district general hospital and a sports injuries clinic. $\mathrm{Br}$ J Sports Med. 2001:35:445-7.

35. Leetun DT, Ireland ML, Willson JD, Ballantyne BT, Davis IM. Core stability measures as risk factors for lower extremity injury in athletes. Med Sci Sports Exerc. 2004;36:926-34

36. Hagglund $M$, Walden $M$, Ekstrand J. Previous injury as a risk factor for injury in elite football: a prospective study over two consecutive seasons. $\mathrm{Br} J$ Sports Med. 2006;40:767-72.

37. Ivarsson A, Johnson U. Psychological factors as predictors of injuries among senior soccer players. A prospective study. J Sports Sci Med. 2010;9:347-52.

38. Junge $A$. The influence of psychological factors on sports injuries. Review of the literature. Am J Sports Med. 2000;28:S10-5.

39. Bahr R, Holme I. Risk factors for sports injuries-a methodological approach. Br J Sports Med. 2003;37:384-92.

40. Orchard JW. Intrinsic and extrinsic risk factors for muscle strains in Australian football. Am J Sports Med. 2001;29:300-3.

41. Doherty C, Bleakley C, Hertel J, Caulfield B, Ryan J, Delahunt E. Lower extremity function during gait in participants with first time acute lateral ankle sprain compared to controls. J Electromyogr Kinesiol. 2015;25:182-92.

42. de Noronha M, Refshauge KM, Herbert RD, Kilbreath SL, Hertel J. Do voluntary strength, proprioception, range of motion, or postural sway predict occurrence of lateral ankle sprain? Br J Sports Med. 2006;40:824-8. discussion 828.

43. Doherty C, Bleakley C, Hertel J, Caulfield B, Ryan J, Sweeney K, Delahunt E. Inter-joint coordination strategies during unilateral stance 6-months following first-time lateral ankle sprain. Clin Biomech (Bristol, Avon). 2015;30:129-35.

44. Doherty C, Bleakley C, Hertel J, Caulfield B, Ryan J, Sweeney K, Patterson MR, Delahunt E. Coordination and symmetry patterns during the drop vertical jump, 6-months after first-time lateral ankle sprain. J Orthop Res. 2015:33:1537-44.

45. Labovitz JM, Yu J, Kim C. The role of hamstring tightness in plantar fasciitis. Foot Ankle Spec. 2011:4:141-4.

46. Ferran NA, Oliva F, Maffulli N. Ankle instability. Sports Med Arthrosc 2009:17:139-45.

47. Maffulli N, Ferran NA. Management of acute and chronic ankle instability. J Am Acad Orthop Surg. 2008;16:608-15.

48. Hiller CE, Nightingale EJ, Lin CW, Coughlan GF, Caulfield B, Delahunt E. Characteristics of people with recurrent ankle sprains: a systematic review with meta-analysis. Br J Sports Med. 2011;45:660-72.

49. Beckman SM, Buchanan TS. Ankle inversion injury and hypermobility: effect on hip and ankle muscle electromyography onset latency. Arch Phys Med Rehabil. 1995;76:1138-43.

50. Bullock-Saxton JE. Local sensation changes and altered hip muscle function following severe ankle sprain. Phys Ther. 1994;74:17-28. discussion 28-31.

51. Bullock-Saxton JE, Janda V, Bullock MI. The influence of ankle sprain injury on muscle activation during hip extension. Int J Sports Med. 1994;15:330-4.

52. Gehring D, Faschian K, Lauber B, Lohrer H, Nauck T, Gollhofer A. Mechanical instability destabilises the ankle joint directly in the ankle-sprain mechanism. Br J Sports Med. 2014:48:377-82.

53. Dominguez L, Leos H, Arellano J. Rehabilitacion de fasciitis plantar cronica. Acta Médica Grupo Ángeles. 2007:5:9-16.

54. Chandler TJ, Kibler WB. A biomechanical approach to the prevention, treatment and rehabilitation of plantar fasciitis. Sports Med. 1993;15:344-52.

55. Harty J, Soffe K, O'Toole G, Stephens MM. The role of hamstring tightness in plantar fasciitis. Foot Ankle Int. 2005;26:1089-92. 